\title{
Sintesis Precipitate Calsium Carbonat Sebagai Filler Pada Plastik Ramah Lingkungan
}

\author{
Sri Elfina ${ }^{1}$, Novesar Jamarun ${ }^{2}$, Syukri Arief ${ }^{2}$, Akmal Djamaan ${ }^{3}$ \\ ${ }^{1}$ Jurusan Analisis Kimia, Politeknik ATI Padang, Jl. Bungo Pasang Tabing Padang 25171, Indonesia \\ ${ }^{2}$ Fakultas Matematika dan Ilmu Pengetahuan Alam, Universitas Andalas, Kampus Limau Manis, Padang 25163, Indonesia \\ ${ }^{3}$ Fakultas Farmasi, Universitas Andalas, Kampus Limau Manis, Padang 25163, Indonesia
}

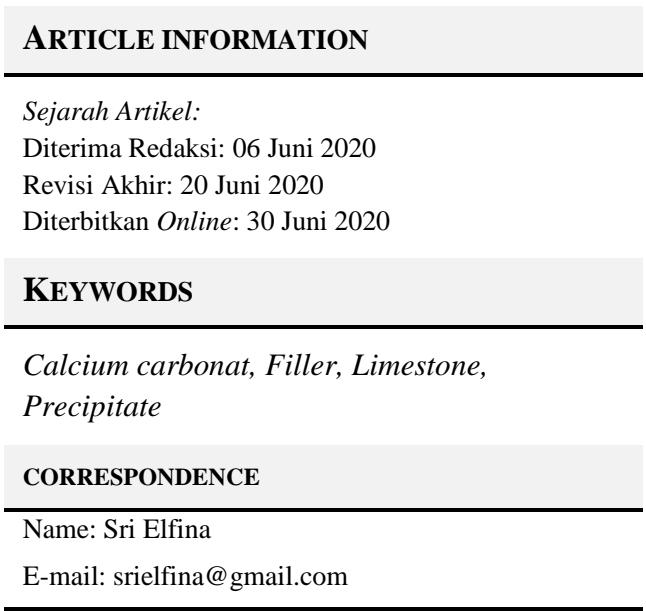

\section{PENDAHULUAN}

Sebagai negara yang dikenal dengan sebutan Nusantara, Indonesia memiliki keuntungan dengan melimpahnya sumber daya alam yang mengandung kalsium, baik yang berada di darat atau di laut. Salah satu sumber kalsium di darat adalah batu gamping atau batu kapur. Batu kapur di alam terjadi secara organik, berasal dari pengendapan cangkang/rumah kerang dan siput, foraminifera atau ganggang [Ghafar, 2017]. Batu kapur mengandung sebagian besar mineral kalsium dalam bentuk $\mathrm{CaCO}_{3}$, (sebagai $\mathrm{CaO}$ sekitar 50,4 - 57\%). Batu kapur, merupakan bahan tambang yang ketersediaannya sangat melimpah di Indonesia terutama daerah Sumatera Barat.

Kandungan kalsium dalam batu kapur dapat dimanfaatkan untuk sintesis Precipitated Calcium Carbonate (PCC). PCC adalah senyawa kalsium karbonat akan tetapi memiliki struktur yang khas, berbeda dengan kalsium karbonat lain. Keistimewaan $P C C$ adalah tingkat kemurniannya sangat tinggi sehingga banyak digunakan pada industri kertas sebagai filler (pengisi) dan coating (pelapis) pigmen, pada plastik sebagai komponen untuk memberikan kekakuan pada PVC [Arief, 2009; Kamba et al, 2013; Kemperl,
2009; Sari et al, 2014; Jamarun et al, 2015]. Sintesis PCC dengan metode karbonasi yang dimodifikasi dengan penambahan asam anorganik pada proses hidrasi (slaking) Arief [2009]. Penambahan PCC diharapkan dapat meningkatkan kekakuan plastik yang terlalu lentur, mengurangi keelastisan dan kecen-derungan untuk bengkok [Widyaningsih, 2012; Elfina, 2018]. Penelitian ini memanfaatkan kalsium dari batu kapur sebagai raw material untuk sintesis PCC, yang digunakan sebagai bahan pengisi atau filler pada pembuatan Plastik ramah lingkungan.

\section{METODOLOGI}

\begin{abstract}
Alat dan Bahan
Bahan-bahan yang digunakan pada penelitian ini yaitu pati, batu kapur Bukit Karang Putih Padang, gliserol 85\% Merck Chemicals made in Germany sebagai pemplastis, Aqua DM (Brataco Chemica), gas $\mathrm{CO}_{2}$, $\mathrm{HNO}_{3}$ (Merck), $\mathrm{NH}_{4} \mathrm{OH}$ (Merck), serta bahan-bahan kimia untuk analisis. Peralatan yang digunakan meliputi peralatan gelas dan plastik, shaker, kraser, hot plate, magnetic stirrer, oven, termometer, neraca analitik, furnace.
\end{abstract}


Alat yang digunakan untuk karakterisasi PCC adalah FTIR - Bruker Tensor 27 series spectrometer, Surface Area Analyzer (SAA, Quantachrome Nova-Win2), Difraktometer sinar X (XRD X'Pert Powder DY 3688), SEM-EDX, (JSM-6510LA, JEOL Japan) dan Atomic force microscopy (AFM NanoSurf, EasyScan2) untuk karakterisasi plastik ramah lingkungan.

\section{Prosedur}

Batu kapur sejumlah $2 \mathrm{~kg}$ dihaluskan dengan kraser dan diayak dengan ukuran $90 \mu \mathrm{m}$ kemudian dikalsinasi pada suhu $900^{\circ} \mathrm{C}$ selama 5 jam (sampai berat konstant) dan didinginkan dalam desikator. Sebanyak 16,8gram sampel hasil kalsinasi yang telah didinginkan dalam desikator dilarutkan dalam $300 \mathrm{~mL} \mathrm{HNO}_{3} 2 \mathrm{M}$ dan diaduk kemudian disaring. pH larutannya dikontrol dan diaduk dengan magnetic stirrer selama 30 menit dengan kecepatan $700 \mathrm{rpm}$ kemudian dikontrol lagi pHnya. Filtrat tersebut ditambahkan $\mathrm{NH}_{4} \mathrm{OH}$ sampai $\mathrm{pH} 12$ dan dialirkan gas $\mathrm{CO}_{2}$ sampai $\mathrm{pH}$ 8. Endapan putih PCC yang terbentuk disaring dan bilas dengan air suling hingga $\mathrm{pH}$ netral. $\mathrm{PCC}$ dikeringkan dalam oven pada suhu $105^{\circ} \mathrm{C}$ selama 3 jam. PCC dikarakterisasi dengan FTIR, XRD, SAA dan SEM-EDX.

Pati ditambahkan aquades, gliserol dan filler PCC kemudian diaduk, dipanaskan, didinginkan dan dikeringkan dengan oven sehingga menjadi plastik ramah lingkungan. Plastik ramah lingkungan yang terbentuk kemudian dikarakterisasi topologi permukaannya dengan menggunakan instrumen AFM.

\section{HASIL DAN PEMBAHASAN}

\section{Analisis PCC}

PCC dari batu kapur diperoleh dengan sintesis menggunakan metode karbonasi. PCC yang telah terbentuk dikarakterisasi dengan FTIR untuk menentukan gugus fungsinya, struktur kristal dikarakterisasi dengan menggunakan difraksi sinar-X, luas permukaan ditentukan dengan SAA, karakterisasi morfologi dengan SEM dan analisis kandungan unsur dengan EDX

\section{Analisis Gugus Fungsi}

Spektra FTIR PCC dari batu kapur ditampilkan pada Gambar 1. Analisis spektroskopi PCC dengan FTIR, dilakukan untuk karakterisasi serapan gugus $\mathrm{CO}_{3}{ }^{2-}$. Munculnya puncak serapan pada daerah $1433 \mathrm{~cm}^{-1}$ dan $862 \mathrm{~cm}^{-1}$, menunjukkan serapan gugus $\mathrm{CO}_{3}{ }^{2-}$ dari $\mathrm{CaCO}_{3}$, mempertegas bahwa senyawa hasil sintesis dari batu kapur adalah PCC. (kirboga, 2013; Deglet, 2016) Spektrum FTIR juga menunjuk-kan puncak serapan khas kalsit sekitar $1433 \mathrm{~cm}^{-1}, 861 \mathrm{~cm}^{-1}, 711 \mathrm{~cm}^{-1}$ dan $857 \mathrm{~cm}^{-1}$ untuk fase aragonite.

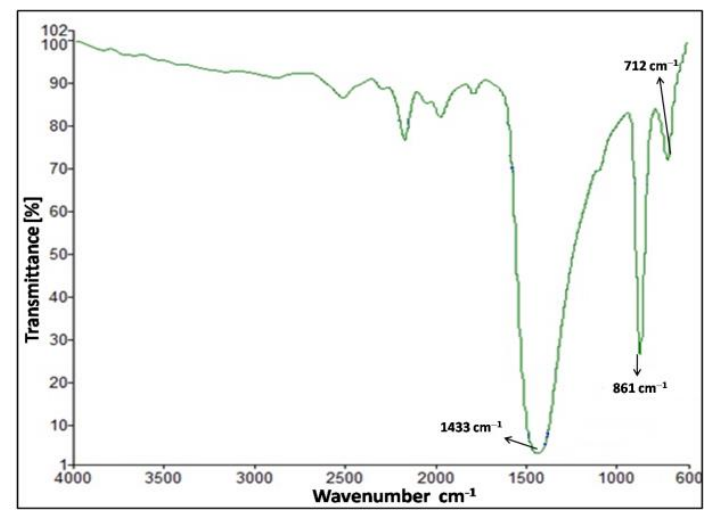

Gambar 1. Pola spektrum FTIR Precipitate Calcium Carbonat

Pola spektrum FTIR PCC dari batu kapur sangat mirip dengan pola spektrum FTIR $\mathrm{CaCO}_{3}$ standar (Shimadzu No. A416) dan pola FTIR PCC yang digunakan sebagai filler pada polipropilena (PP) [Lam, 2008].

\section{Analisis Struktur dan Ukuran Kristal}

Ukuran kristal PCC dianalisis dari data XRD menggunakan persamaan Scherrer (1).

$$
\boldsymbol{D}=\frac{\boldsymbol{k} \cdot \boldsymbol{\lambda}}{\boldsymbol{\beta} \cdot \operatorname{Cos} \boldsymbol{\theta}}
$$

Dimana $D$ adalah ukuran kristalit (nm), $\beta$ adalah Full Width at Half Maximum (FWHM) atau pelebaran setengah intensitas maksimum dalam radian, $\mathrm{k}$ adalah konstanta Scherrer dengan nilai $0,9-1, \lambda$ adalah panjang gelombang sinar $\mathrm{X}$ dari radiasi $\mathrm{CuK} \alpha$, yakni 0,15406 (nm), dan $\theta$ adalah sudut Bragg. Diperoleh ukuran kristal Precipitate Calcium Carbonat dari batu kapur berkisar antara $20-28 \mathrm{~nm}$. Pada Gambar 2 diperlihatkan hasil analisis XRD untuk (a) PCC dari batu kapur, (b) calcite standar dan (c) aragonite standar.

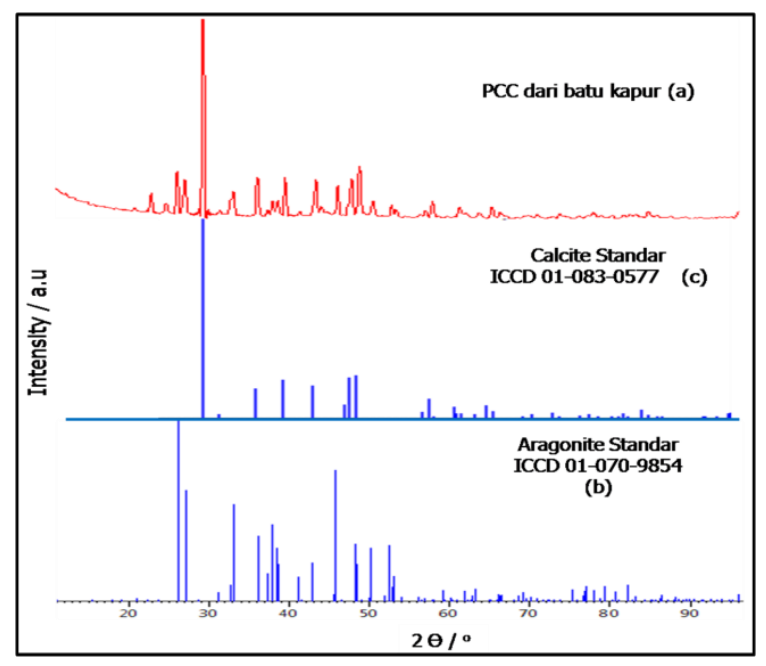

Gambar 2. Hasil Analisis XRD Precipitate Calcium Carbonat dan ICDD

Karakterisasi dengan XRD adalah untuk mengetahui jenis kristal yang terkandung dalam material. Kristal kalsium karbonat $\left(\mathrm{CaCO}_{3}\right)$ terdiri atas 3 fasa, yaitu fasa calcite, aragonite dan veterite. Masing-masing kristal memiliki sudut difraksi dan indek miller yang berbeda- 
beda. Bentuk kristal PCC pada Gambar 2 adalah campuran antara calcite dan aragonite. Hal ini didukung dengan puncak difraksi maximum 2 theta dengan nilai $29,41^{\circ}(100 \%)$ (104) puncak kalsit yang tajam [Zou, 2017]; $39,46^{\circ}(113) ; 43,23^{\circ}(202)$ dan $47,56^{\circ}(018)$ yang merupakan fasa calcite. Namun juga terdapat puncak difraksi lain yang menunjukkan bentuk kristal PCC aragonite yaitu pada sudut 2 theta $26,19^{\circ}(100 \%)(111)$; $27,13^{\circ}(102) ; 33,18^{\circ}(201) ; 36,00^{\circ}(020) ; 37,82^{\circ}(211)$; $45,88^{\circ}$ (122) dan $48,50^{\circ}$ (220). Hal ini juga didukung dengan nilai-nilai puncak difraksi. Dimana nilai tersebut tidak jauh berbeda jika dibandingkan dengan data standar yaitu data International Centre Data Diffraction (ICDD) No. 01-083-0577 untuk fasa calcite dan ICDD No. 01-070-9854 untuk fasa aragonite, seperti ditampilkan pada Tabel 1.

\begin{tabular}{|c|c|c|c|c|c|c|c|c|c|c|c|}
\hline \multirow{3}{*}{ NO } & \multirow{2}{*}{\multicolumn{2}{|c|}{$\begin{array}{l}\text { Hasil pengukuran } \\
\text { precipitate calcium } \\
\text { carbonat }\end{array}$}} & \multicolumn{4}{|c|}{ Database } & \multirow{3}{*}{$\begin{array}{l}\text { Fasa } \\
\text { kristal }\end{array}$} & \multirow{3}{*}{ FWHM } & \multirow{3}{*}{$\begin{array}{c}\boldsymbol{\beta} \\
\text { (Radian) }\end{array}$} & \multirow{3}{*}{$\mathrm{D}(\mathrm{nm})$} & \multirow{3}{*}{$\begin{array}{l}\text { Indeks } \\
\text { Miller }\end{array}$} \\
\hline & & & \multicolumn{2}{|c|}{ Calcite } & \multicolumn{2}{|c|}{ Aragonite } & & & & & \\
\hline & 2 Theta & $\begin{array}{l}\text { I REI } \\
(\%)\end{array}$ & 2 Theta & $\begin{array}{c}\text { I REI } \\
(\%)\end{array}$ & 2 Theta & $\begin{array}{l}\text { I REI } \\
(\%)\end{array}$ & & & & & \\
\hline 1 & 26,19 & 20,49 & - & - & 26,22 & 100 & Aragonite & 0,3542 & 0,0062 & 23 & 111 \\
\hline 2 & 27,13 & 16,90 & - & - & 27,22 & 57 & Aragonite & 0,3739 & 0,0065 & 22 & 102 \\
\hline 3 & 29,41 & 100 & 29,41 & 100 & - & - & Calcite & 0,4133 & 0,0072 & 20 & 104 \\
\hline 4 & 33,18 & 10,39 & - & - & 33,15 & 50 & Aragonite & 0,2952 & 0,0052 & 28 & 201 \\
\hline 5 & 36,00 & 18,48 & - & - & 36,17 & 33 & Aragonite & 0,3936 & 0,0069 & 21 & 020 \\
\hline 6 & 37,82 & 6,89 & - & - & 37,90 & 39 & Aragonite & 0,3346 & 0,0058 & 25 & 211 \\
\hline 7 & 39,46 & 18,59 & 39,41 & 18 & - & - & Calcite & 0,3346 & 0,0058 & 25 & 113 \\
\hline 8 & 43,23 & 17,40 & 43,16 & 15 & - & - & Calcite & 0,3542 & 0,0062 & 24 & 202 \\
\hline 9 & 45,88 & 15,34 & - & - & 45,86 & 67 & Aragonite & 0,3542 & 0,0062 & 24 & 122 \\
\hline 10 & 47,56 & 18,34 & 47,52 & 19 & - & - & Calcite & 0,3346 & 0,0058 & 26 & 018 \\
\hline 11 & 48,50 & 24,69 & - & - & 48,46 & 19 & Aragonite & 0,3936 & 0,0069 & 22 & 220 \\
\hline
\end{tabular}

\section{Karakterisasi Luas Permukaan}

Surface Area Analyzer digunakan untuk mengetahui karakter material yang didasarkan pada proses adsropsi/desorpsi, umumnya dengan metode BrunauerEmmett-Teller (BET) menggunakan gas nitrogen sebagai adsorben pada suhu 77K. Pada penelitian ini analisis SAA PCC dari batu kapur meliputi luas permukaan spesifik, luas permukaan BET, ukuran pori dan total volume pori.

Hasil analisis SAA PCC disajikan dalam bentuk kurva isotherm adsopsi /desorpsi yang diperoleh sebagai hasil plot volume adsorbat sebagai tekanan relatif $\left(\mathrm{P} / \mathrm{P}_{\mathrm{o}}\right)$ seperti ditunjukan pada Gambar 3.

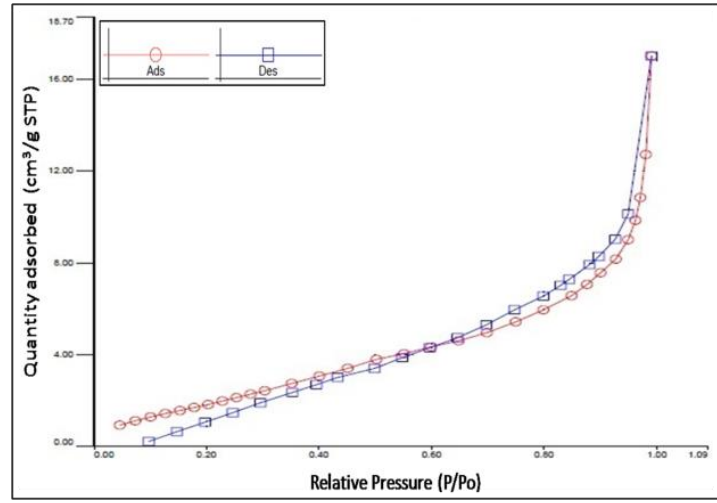

Gambar 3. Isoterm adsorpsi-desorpsi Nitrogen pada $P C C$

Isoterm menunjukkan peningkatan yang lambat dalam jumlah nitrogen yang teradsorpsi. Menurut klasifikasi IUPAC, isoterm adsorpsi nitrogen yang teramati dapat diidentifikasi sebagai tipe III. Tipe ini sesuai dengan material yang memiliki pori seperti PCC yang digunakan sebagai filler pada Plastik ramah lingkungan. Kurva distribusi ukuran pori yang diperoleh dari volume pori adsorpsi dengan metode Barrett, Joyner and Halenda (BJH) ditunjukkan pada Gambar 4 berikut.

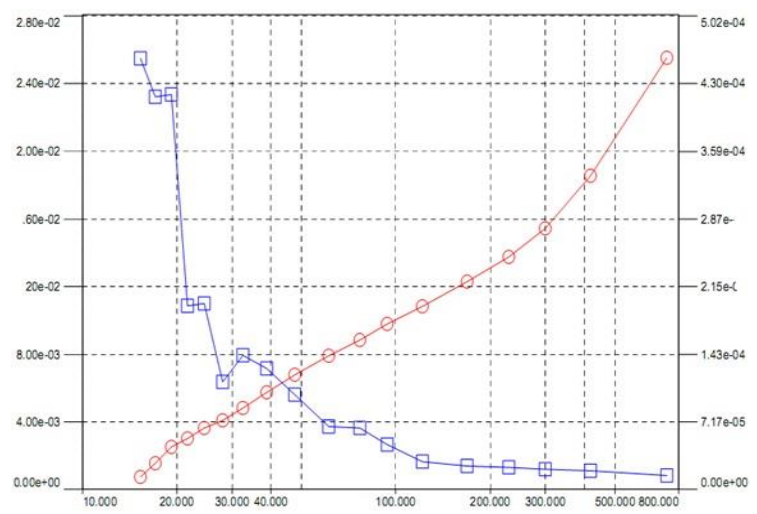

Gambar 4. BJH distribusi pori Precipitate Calcium Carbonat

Gambar 4. menunjukan bahwa $P C C$ dari batu kapur memiliki ukuran pori $62,996 \AA$. Berdasarkan klasifikasi IUPAC 1985 ukuran pori PCC ini termasuk kelompok material mesopori [Thommes et al., 2015]. Untuk kelompok mesopori umumnya pengisian pori pada proses adsorpsi terjadi dengan cara kondensasi pori melalui transisi fase gas-cair. Perilaku penyerapan ini tergantung pada daya tarik dinding fluida dan interaksi dalam cairan sehingga dapat menyebabkan terjadinya adsorpsi multilayer dan kondensasi kapiler. Kondisi ini sering disertai hysteresis yang teramati pada pori tunggal dan pori jaringan [Thommes, 2014]. 
Selain data ukuran pori dan tipe isotherm yang terjadi, metode BET cara adsorpsi nitrogen pada suhu $77 \mathrm{~K}$ juga akurat untuk menentukan luas permukaan spesifik, luas

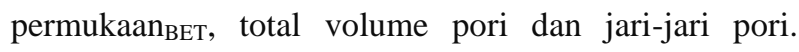
Parameter tekstur hasil pengukuran seperti tertera pada Tabel 2.

Tabel 2. Parameter tekstur yang dihitung dari $\mathrm{N}_{2}$ isoterm adsorpsi precipitate calcium carbonat

\begin{tabular}{ll}
\hline Parameter & Nilai \\
\hline Luas permukaaan spesifik & $7,315 \mathrm{~m}^{2} \mathrm{~g}^{-1}$ \\
Luas permukaan & $\mathrm{BET}$ \\
Total volume pori & $8,343 \mathrm{~m}^{2} \mathrm{~g}^{-1}$ \\
Jari-jari pori & $2,628 \times 10^{-2} \mathrm{~cm}^{3} \mathrm{~g}^{-1}$ \\
\hline
\end{tabular}

Karakteristik permukaan yang disajikan pada Tabel 2 menunjukkan bahwa sampel memiliki sifat yang tidak jauh berbeda antara lapisan atas dan lapisan di bawahnya. Hal ini ditunjukan oleh luas permukaan spesifik dan luas permukaan вет $P C C$.

\section{Analisis Kandungan Unsur dan Morfologi Permukaan}

Morfologi permukaan $P C C$ hasil analisis SEM dan mikrograf $P C C$ dengan perbesaran yang berbeda disajikan pada Gambar 5.

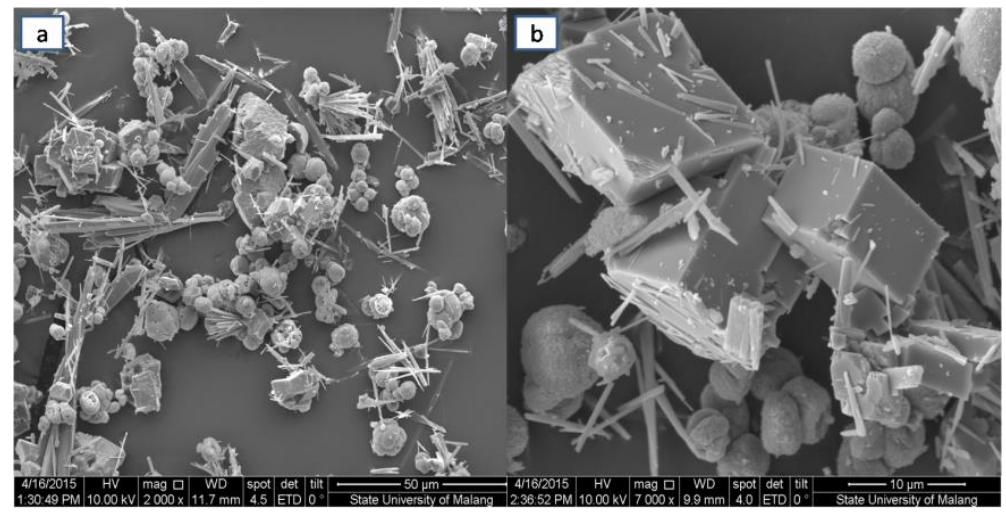

Gambar 5. Foto SEM PCC dari batu kapur (a) perbesaran $2.000 \mathrm{x}$ dan (b) perbesaran $7.000 \mathrm{x}$

Gambar 5 menunjukan mikrograf $P C C$ yang diperoleh adalah jenis kristal kalsit [Elfina, 2006] dan aragonite [Kamba et al., 2013; Yang, 2017], dapat dilihat dari bentuknya seperti persegi untuk kristal kalsit dan berbentuk jarum untuk kristal aragonit. Hasil morfologi partikel PCC konsisten dengan pola XRD (Gambar 2).

Partikel berbentuk bulat pada Gambar 5 mirip dengan PCC yang dilakukan oleh Xiang [2002]. Partikel PCC berukuran mikrometer atau partikel super halus dengan bentuk partikel bulat dan diameter rata-rata sekitar 0,15 $\mu \mathrm{m}$ dapat disintesis secara langsung bahkan tanpa penambahan bahan kimia. Pola difraksi sinar-X pada produk PCC tanpa penambahan bahan kimia merupakan karakteristik fase kalsit [Xiang, 2002; Jimoh, 2017].

Selain untuk morfologi permukaan, analisis SEM yang dilengkapi dengan EDX dapat digunakan untuk mengetahui komponen atau unsur yang terdapat dalam sampel. Hasil analisis unsur PCC berdasarkan data EDX ditampilkan pada Gambar 6.

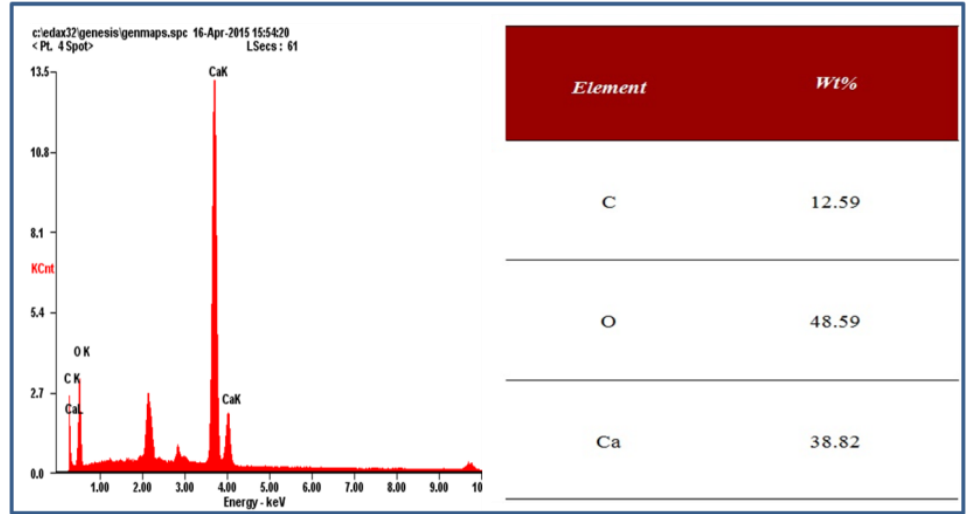

Gambar 6. Kandungan unsur dalam Precipitate Calcium Carbonat dari Batu kapur

Pada Gambar 6 dilihat unsur penyusun $P C C$ adalah $\mathrm{C}$, $\mathrm{O}$ dan $\mathrm{Ca}$ serta tidak ditemukannya unsur lain. Analisis ini sesuai dengan yang telah dipaparkan oleh Elfina [2006].
Berdasarkan analisis XRD, FTIR dan SEM-EDX, dapat disimpulkan bahwa senyawa hasil sintesis dari $\mathrm{CaO}$ batu kapur adalah $P C C$ dengan jenis kristal aragonit dan kalsit.

4 Elfina et al. 


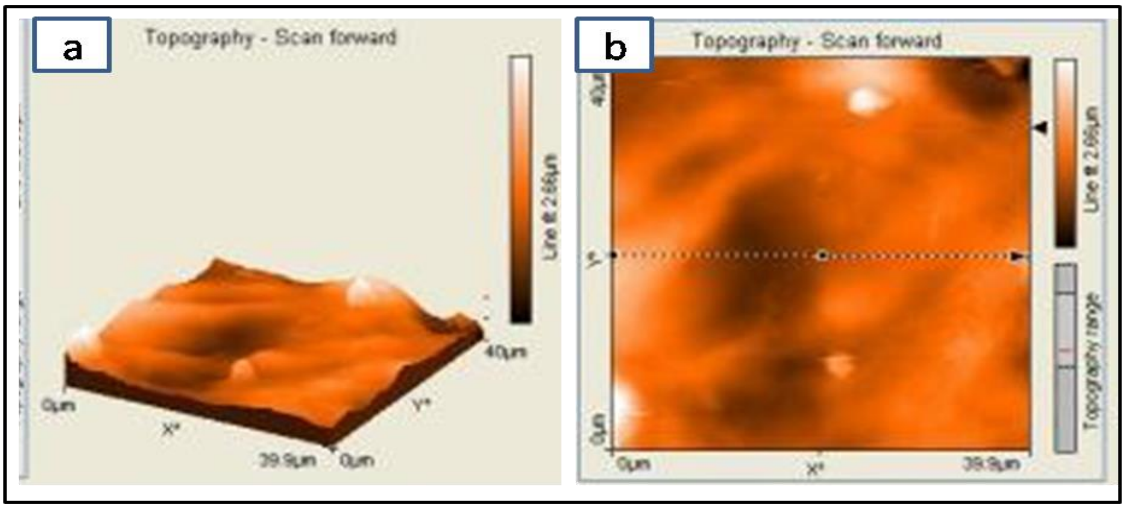

Gambar 7. AFM Plastik ramah lingkungan dengan penambahan filler Precipitate Calcium Carbonat

\section{Analisis Topologi dan Kekasaran Permukaan Plastik ramah lingkungan}

Pemindaian AFM terhadap Plastik ramah lingkungan dengan penambahan filler PCC seperti dapat dilihat pada Gambar 7 menunjukkan permukaan yang memperlihatkan formasi dengan masih terdapatnya globular. Topografi-scan menggambarkan bentuk permukaan dalam ukuran nanometer yang menggambarkan puncak-puncak yang datar /halus dengan kecerahan yang seragam. Analisis ketebalan memperlihat-kan ketebalan yang rata-rata sama tinggi. Analisis tingkat perkembangan bantuan menggunakan parameter mean kekasaran persegi menunjukkan bahwa permukaan Plastik ramah lingkungan dengan penambahan filler PCC memiliki nilai $\mathrm{Rq} 0,43 \mu \mathrm{m}$, dimana tanpa penambahan filler PCC memiliki nilai $\mathrm{Rq} 1,02$ $\mu \mathrm{m}$.

\section{KESIMPULAN}

Hasil sintesis Filler PCC dari batu kapur berdasarkan hasil analisis X-RD, FTIR dan SEM-EDX, dapat disimpulkan bahwa senyawa hasil sintesis dari $\mathrm{CaO}$ batu kapur adalah Precipitate Calcium Carbonat dengan jenis kristal aragonit dan kalsit.

Karakterisasi Precipitate Calcium Carbonat yang dihasilkan dengan menggunakan peralatan BET dan AFM menunjukan bahwa Precipitate Calcium Carbonat, dapat digunakan sebagai bahan pengisi atau filler pada pembuatan Plastik ramah lingkungan, karena memiliki puncak yang lebih datar/halus dengan kecerahan yang seragam.

\section{DAFTAR PUSTAKA}

Arief, S dan N. Jamarun, 2009. Studi Pembentukan Precipitated Calcium Carbonate (PCC) dari Batu Kapur Alam Sumatera Barat. Penelitian Hibah Strategis Nasional.

Declet, A., E. Reyes and O.M. Suàrez. 2016. Calcium Carbonate Precipitation: A Review of the Carbonate Crystallization Process and Application in Bioinspired Composites. Rev. Adv. Mater Sci. 44: 87-107

Elfina, S. 2006. Pembuatan PCC dengan penambahan $\mathrm{HCl}$ dari batu kapur beberapa daerah di Sumatera
Barat menggunakan metode karbonasi. Tesis. Universitas Andalas Padang

Elfina, S. 2018. Bioplastik Ramah Lingkungan Dari Pati Bengkuang (Pachyrrizus erosus) Dengan Penambahan Precipitate Calcium Carbonat Dan Hidroksiapatit Sebagai Filler". Disertasi. Universitas Andalas Padang

Ghafar, S.L.M.A., M.Z. Hussein, and Z.A. Bakar Zakaria. 2017. Synthesis and Characterization of Cockle Shell-Based Calcium Carbonate Aragonite Polymorph Nanoparticles with Surface Functionalization. Hindawi Journal of Nanoparticles. 8196172. 1-12

Jamarun, N., S. Yuwan, R. Juita and J. Rahayuningsih. 2015. Synthesis And Characterization Carbonate Apatite From Bukit Tui Limestone Padang Indonesia. Journal of Applicable Chemistry. 4: 542-549

Jimoh, O.A., T.A.H. Hussin, K.S. Ariffin and N. Baharun. 2017. Understanding the Precipitated Calcium Carbonate (PCC) Production Mechanism and Its Characteristics in the Liquid-Gas System Using Milk of Lime (MOL) Suspension. South African Journal of. Chemistry. 70: 1-7

Kamba, A.S., T.A. Ibrahim, M. Ismail, and Z.A.B. Zakaria. 2013. Synthesis and Characterisation of Calcium Carbonate Aragonite Nanocrystals from Cockle Shell Powder (Anadara granosa). Journal of Nanomaterials. Article ID 398357.9 pages

Kemperl, J. and J. Macek. 2009. Precipitation of calcium carbonate from hydrated lime of variable reactivity, granulation and optical properties. International Journal of Mineral Processing. 93: 84-88

Kirboga, S and M. Oner. 2013. Effect on the experimental parameters on calcium carbonate precipitation. Journal Chemical Engineering Transactions. 32: 2119-2123

Lam, T.D., T.V. Hoang, D.T. Quang and J.S. Kim. 2008. Effect of nanosized and surface-modified precipitated calcium carbonate on properties of $\mathrm{CaCO} /$ polypropylene nanocomposites. Journal Materials Science and Engineering. MSA-24559: $1-7$.

Rohrbeck, M., C. Fischer, S. Wehner, J. Meier and W. Manz. 2014. DLC-coated pure bioplastic foil 
Effect of various sterilization methods on the surface morphology. VIP Journal. 26: 42-47

Sari, T.P., N. Jamarun, S. Arief, Z. Azharman and A. Asril. 2014. Effect of Mixing Temperature on the Synthesis of Hydroxyapatite by Sol-gel Method. Oriental Journal of Chemistry. 30: 1799-1804

Thommes, M. and K.A. Cychosz. 2014. Physical Adsorption Characterization of Nanoporous Material: Progress and Challenges. Adsorption. 20: 233-250

Thommes, M.K., A.V. Kaneko, J.P. Neinmark, F. Olivier, Rodriguez-reinoso, J. Rouquerol and K.S.W. Sing. 2015. Physisorption of gases, with Special Reference to the Evaluation of Surface Area and Pore Size Distribution (IUPAC Technical Report). Pure Appl. Chem. Aop: 1-19

Widyaningsih, S., D. Kartika., Y.T. Nurhayati. 2012. Pengaruh Penambahan Sorbitol dan Kalsium Karbonat terhadap Karakteristik dan Sifat
Biodegradasi Film dari Pati Kulit Pisang. Jurnal Molekul. 7(1): 69-81

Xiang, L., Y. Xiang, Z.G. Wang and Y. Jin. 2002. Influence of chemical additives on the formation of super-fine calcium carbonate. Powder Technology. 126: 129-133.

Yang, C., J. Zhang, W. Li, S. Shang and C. Guo. 2017. Synthesis of aragonite $\mathrm{CaCO}_{3}$ nano crystals by reactive crystallization in a high shear mixer. Crystal Research and Technology Journal. 1-7.

Zinoviev, E., R. Rakhmatullin and I. Almazov. 2014. New Bioplastic Material Based on Hyaluronic Acid Hydrocolloid. Journal Clinical \& Experimental Dermatology Research. 5(2): 1-3

Zou, Z., L. Bertinetti, Y. Politi, P. Fratzl and W.J.E.M. Habraken. 2017. Control of Polymorph Selection in Amorphous Calcium Carbonate Crystallization by Poly(Aspartic Acid): Two Different Mechanisms. Nano Micro Small Journal. 1603100: $1-1$ 